\title{
Initial and Repeat Screening for Chlamydia trachomatis During Pregnancy
}

\author{
Alexander D. Allaire, ${ }^{1 *}$ John F. Huddleston, ${ }^{2}$ William L. Graves, ${ }^{3}$ and \\ Lawrence Nathan ${ }^{3}$ \\ ${ }^{1}$ Department of Obstetrics and Gynecology, University of North Carolina at Chapel Hill, \\ Chapel Hill, $N G$ \\ ${ }^{2}$ Department of Obstetrics and Gynecology, University of Florida at Jacksonville, Jacksonville, FL \\ ${ }^{3}$ Department of Gynecology and Obstetrics, Grady Memorial Hospital, Emory University School of \\ Medicine, Atlanta, GA
}

\begin{abstract}
Objectives: The objective of this study is to determine the prevalence of Chlamydia trachomatis and risk factors for positive repeat tests in a high-risk population presenting for early prenatal care.

Methods: We completed a retrospective cohort study of 2,484 women who initiated prenatal care prior to 20 weeks gestation, delivered, and received testing for cervical C. trachomatis at Grady Memorial Hospital or a Grady-affiliated clinic between July 1, 1993 and December 31, 1994. We calculated adjusted odds ratios (OR) for selected risk factors for a positive initial test and for a positive subsequent test after an initial negative test.

Results: The prevalence of $C$. trachomatis was $14.8 \%$. At initial testing, $10.4 \%$ of the women were positive. If the initial test was negative, $5.7 \%$ had a positive subsequent test; but if the initial test was positive, $32.0 \%$ had a positive subsequent test $(P<0.001)$. The variables significantly and independently associated with a positive initial test were black race/ethnicity, age less than 25 , unmarried, and less than a high-school education (adjusted OR of 1.66, 3.53, 2.18, and 1.81, respectively). Variables significantly and independently associated with a positive subsequent test after a negative initial test were white race/ethnicity, black race/ethnicity, age less than 25 , and less than a highschool education (adjusted OR 8.69, 7.77, 4.12, and 2.27, respectively).

Conclusions: In our inner-city population, most pregnant women have risk factors suggesting the need to rescreen for C. trachomatis in the second half of pregnancy. Infect. Dis. Obstet. Gynecol. 6:116-122, 1998. @ 1998 Wiley-Liss, Inc.
\end{abstract}

\section{KEY WORDS}

chlamydia; risk factors; screening test

C

hlamydia trachomatis is the most common, reportable sexually transmitted disease in the United States. ${ }^{1}$ It is estimated that of sexually active women, $4 \%-5 \%$ are currently infected with this organism. ${ }^{2}$ In pregnant women, the prevalence of $C$. trachomatis ranges from $2 \%-30 \% .^{3-5}$ Risk factors for acquiring $C$. trachomatis include multiple sex partners, a new sexual partner in the preceding three months, young age ( $<25$ years), unmarried status, low parity, nonbarrier contraception, low socioeconomic status, receiving care at public health clinics, nonwhite race, and past history or presence of other sexually transmitted diseases. ${ }^{3-6}$

The obstetric significance of $C$. trachomatis cervical infection has been well-studied. The presence of this organism has been associated with the

*Correspondence to: Dr. Alexander D. Allaire, Department of Obstetrics and Gynecology, University of North Carolina, 214 MacNider Building, Chapel Hill, NC 27599-7570. 
perinatal complications of premature rupture of membranes (PROM), preterm labor and birth, low birth weight, intrauterine growth retardation, stillbirth, and postpartum and postabortal endometritis. ${ }^{3,7-15}$ Following passage through an infected birth canal, an infant has considerable risk of acquiring $C$. trachomatis. An infant delivered to a woman infected with this organism present in the cervix risks acquiring pneumonitis, (3\%-18\%), conjunctivitis (18\%-50\%), and nasopharyngeal infection $(15 \%-20 \%){ }^{16-23}$ Treatment of $G$. trachomatis infection during pregnancy can decrease substantially the development of these maternal and perinatal complications. ${ }^{23}$ It is, therefore, important to identify women with $C$. trachomatis infection during pregnancy.

Because of these maternal and perinatal risks, the Centers for Disease Control (CDC) recommends screening for $C$. trachomatis cervical infection at the first prenatal visit for all pregnant women, whereas the American College of Obstetricians and Gynecologists (ACOG) does not recommend universal screening. ${ }^{1,5}$ Both the CDC and ACOG recommend screening in the third trimester for patients at high risk, although no data are cited to support this recommendation.

At Grady Memorial Hospital in Atlanta, Georgia, the current obstetric policy regarding $C$. trachomatis is to screen all women routinely for cervical infection at their first prenatal visit and to repeat testing at 34 to 36 weeks gestation. A woman is also retested if she presents with preterm labor, preterm PROM, or signs and symptoms of cervical infection. This study investigates the prevalence of positive $C$. trachomatis tests and rate of positive repeat tests throughout gestation in a high-risk population presenting for early prenatal care. In addition, the researchers sought to identify specific risk factors that would suggest a benefit for repeat screening among those gravidas with negative initial screening.

\section{SUBJECTS AND METHODS}

Grady Memorial Hospital cares primarily for indigent patients of Fulton and DeKalb counties, which encompass most of the Atlanta metropolitan area. It also serves as a referral center for patients with complications in metropolitan Atlanta and eight surrounding counties.
Women considered for this study were all those who initiated prenatal care, delivered, and received testing for cervical $C$. trachomatis infection at Grady Memorial Hospital or a Grady-affiliated clinic during the 18-month period from July 1, 1993, through December 31, 1994. Since we were attempting to determine the utility of repeat testing, only patients presenting for prenatal care at less than 20 weeks gestation were included. After study of this initial group, subsequent analysis was confined to the women who actually had follow-up $C$. trachomatis tests later in pregnancy. Cervical $C$. trachomatis screens were performed exclusively with GenProbe (Gen-Probe Incorporated, San Diego, CA) from July 1993 through October 1993. After October 1993, Micro'Trak II Chlamydia EIA (Syva Company, San Jose, CA) was primarily used. Patients were treated without confirmatory $C$. trachomatis cultures. At the time of the study, the majority of patients were treated, according to the current CDC recommendations, ${ }^{1}$ with oral erythromycin in split doses (1 gram/day for 2 weeks or 2 grams/day for 1 week). If allergy to erythromycin was claimed or if intolerance was demonstrated, patients were treated with amoxicillin $(500 \mathrm{mg}$, three times daily for one week). All screening tests were performed in Grady Memorial Hospital's laboratory and were entered into a mainframe computer database. Evaluation of that database allowed identification of all women tested for cervical $G$. trachomatis infection during the study, the date of each test, and the result of each test.

A separate obstetric database is maintained, into which is entered an extensive demographic and medical review of all patients delivered at Grady Memorial Hospital. This obstetric database, which is completed at delivery, includes date of delivery, gestational age at delivery, and selected historical information. Cross-referencing these two distinct databases allowed evaluation of the gestational age at which each test was performed, the number of tests performed on each patient, the result of each test, and the presence of specific demographic and historical variables. If more than one subsequent $C$. trachomatis test was done, any subsequent positive was considered a positive repeat test, so long as that test was performed more than two weeks after the first; this interval was to allow for success of initial drug therapy. Although it was the policy to 
treat the sexual partners of those who tested positive or to refer them for treatment, compliance with this recommendation is not recorded on the database. The relative risk (RR) and adjusted ORs of each variable were determined, with $95 \%$ confidence intervals (CI), for a positive initial test and a positive subsequent test after an negative initial test, by the use of the EPI INFO (CDC, Atlanta, GA) statistical program for univariate and the SPSS (SPSS Inc., Chicago, IL) statistical program for multivariate analysis. Patients who had repeat testing after an negative initial test were compared with patients who did not have repeat testing for the same, previously mentioned variables.

\section{RESULTS}

During the study period, 2,484 women presented for prenatal care prior to 20 weeks gestation and had at least one $C$. trachomatis screening test. On these 2,484 prenatal patients, 5,745 $C$. trachomatis tests were performed ( 1 to 11 tests per patient, with a mean of 2.5). Of these patients, 259 (10.4\%) had a positive initial test, $2,225(89.6 \%)$ had a negative initial test, and 2,173 (87.5\%) had at least one subsequent test. Of the 2,484 patients meeting criteria for initial inclusion, 368 had at least one positive test during pregnancy, for a prevalence of $14.8 \%$ during pregnancy.

Of the 2,225 patients who initially tested negative for $G$. trachomatis, 296 (13.3\%) had no further testing, whereas $1,929(86.7 \%)$ had follow-up testing. Of these 1,929 patients, 109 (5.7\%) subsequently had a positive test, and 1,820 (94.3\%) had negative follow-up tests. Of the 259 patients who had a positive initial test, $15(5.8 \%)$ were tested only once, but 244 (94.2\%) had follow-up testing. Of these 244 patients, $78(32.0 \%)$ had a recurrent positive test during that pregnancy. The percentage of patients who had a subsequent positive test after an initial positive test is significantly higher than the percentage of patients who had a subsequent positive test after an initial negative test (32.0\% vs. $5.7 \%, P<0.001$; RR 5.66, 95\% CI 4.377.33).

Selected risk factors for a positive initial test were assessed. Risk factors independently associated with a positive initial test for $G$. trachomatis during pregnancy were found to be black race (compared to "other," which was primarily His- panic), age less than 25, unmarried status, and less than a high-school education (Table 1).

To determine if health care providers were selectively retesting patients based on demographic or historical risk factors, patients who initially tested negative for $C$. trachomatis and had only one test prior to 20 weeks gestation were compared to patients who initially had a negative test and had repeat screening. Patients who were significantly more likely to have had repeat screening included those who were less than 25 years old (RR 1.05, 95\% CI 1.01-1.08), nulligravid (RR 1.04, 95\% CI 1.01-1.08), and had no prior abortions (RR1.04, 95\% CI 1.01-1.08).

Patients who initially tested negative and had only negative repeat testing were then compared to those who had at least one positive subsequent test. Risk factors independently associated with a positive subsequent test after a negative initial test were of white or black race (compared to "other"), were younger than 25 years, and had less than a high-school education ('Table 2).

\section{COMMENT}

To our knowledge, this is the first study to evaluate the clinical utility of repeated $G$. trachomatis testing in pregnancy. The CDC and ACOG recommend follow-up testing in the third trimester for patients who are at high risk; however, no data are cited. We designed our study to determine whether we could target a high-risk segment of our population for whom subsequent testing would be most efficient. As a cost-saving measure, we had hoped to identify patients for whom subsequent testing could be safely omitted.

The prevalence of a positive, nonculture $C$. trachomatis test at the first prenatal visit was $10.4 \%$, and the overall prevalence during pregnancy was $14.8 \%$ in our population. This prevalence is similar to previously published reports. ${ }^{3}$ Patients with a positive initial test were at significantly higher risk for a positive subsequent test $(32.0 \%)$ than patients who initially tested negative (5.7\%). This finding supports retesting patients who are positive initially, because they are at high risk for reinfection or failed treatment. A weakness of this study's design is that in patients with positive subsequent tests, we were unable to distinguish between reinfection and failed treatment. Although we ex- 
TABLE I. Risk factors associated with a positive initial $C$. trachomatis test during pregnancy

\begin{tabular}{|c|c|c|c|c|}
\hline Risk factor* & $\begin{array}{c}\text { Positive } \\
\text { test }\end{array}$ & $\begin{array}{l}\text { Percent } \\
\text { positive }\end{array}$ & $\begin{array}{c}\mathrm{RR} \\
(95 \% \mathrm{Cl}) \\
\end{array}$ & $\begin{array}{c}\text { Adjusted OR } \\
(95 \% \mathrm{Cl})\end{array}$ \\
\hline \multicolumn{5}{|l|}{ Race/ethnicity $(n=2484)$} \\
\hline Black $(n=1827)$ & 221 & 12.1 & $\begin{array}{c}2.14 \\
(1.49-3.06)\end{array}$ & $\begin{array}{c}1.66 \\
(1.01-2.74)\end{array}$ \\
\hline White $(n=91)$ & 6 & 6.6 & $\begin{array}{c}1.17 \\
(0.50-2.71)\end{array}$ & $\begin{array}{c}0.95 \\
(0.35-2.62)\end{array}$ \\
\hline Other $(n=566)$ & 32 & 5.7 & 1.00 & 1.00 \\
\hline \multicolumn{5}{|l|}{ Age $(n=2484)$} \\
\hline$<25(n=1455)$ & 219 & 15.1 & $\begin{array}{c}3.87 \\
(2.79-5.37)\end{array}$ & $\begin{array}{c}3.53 \\
(2.44-5.09)\end{array}$ \\
\hline$\geq 25(n=1029)$ & 40 & 3.9 & 1.00 & 1.00 \\
\hline \multicolumn{5}{|l|}{ Marital status $(n=2484)$} \\
\hline Not currently married $(n=1805)$ & 230 & 12.7 & $\begin{array}{c}2.98 \\
(2.05-4.35)\end{array}$ & $\begin{array}{c}2.18 \\
(1.32-3.59)\end{array}$ \\
\hline Married $(n=679)$ & 29 & 4.3 & 1.00 & 1.00 \\
\hline \multicolumn{5}{|l|}{ Education $(n=2461)$} \\
\hline$<$ High school $(n=689)$ & 96 & 13.9 & $\begin{array}{c}1.53 \\
(1.21-1.94)\end{array}$ & $\begin{array}{c}1.81 \\
(1.34-2.46)\end{array}$ \\
\hline$\geq$ High school $(n=1722)$ & 156 & 9.1 & 1.00 & 1.00 \\
\hline \multicolumn{5}{|l|}{ Gravidity $(n=2484)$} \\
\hline Nulligravid $(n=820)$ & 117 & 14.3 & $\begin{array}{c}1.67 \\
(1.33-2.10)\end{array}$ & $* *$ \\
\hline At least one pregnancy $(n=1664)$ & 142 & 8.5 & 1.00 & $* *$ \\
\hline \multicolumn{5}{|l|}{ History of preterm $(n=2484)$} \\
\hline Prior preterm $(n=253)$ & 25 & 9.9 & $\begin{array}{c}0.94 \\
(0.64-1.39)\end{array}$ & $* *$ \\
\hline No preterm $(n=2231)$ & 234 & 10.5 & 1.00 & ** \\
\hline \multicolumn{5}{|l|}{ History of abortion $(n=2484)$} \\
\hline No prior abortion $(n=1600)$ & 191 & 11.9 & $\begin{array}{c}1.55 \\
(1.21-2.20)\end{array}$ & ** \\
\hline Prior abortion $(n=884)$ & 68 & 7.7 & 1.00 & $* *$ \\
\hline \multicolumn{5}{|l|}{ Drug use $(n=2484)$} \\
\hline Drug use $(n=99)$ & 9 & 10.5 & $\begin{array}{c}0.87 \\
(0.46-1.63)\end{array}$ & $* *$ \\
\hline No drug use $(n=2385)$ & 250 & 9.1 & 1.00 & ** \\
\hline \multicolumn{5}{|l|}{ Alcohol use $(n=2483)$} \\
\hline Alcohol use $(n=2246)$ & 237 & 10.6 & $\begin{array}{c}0.88 \\
(0.58-1.33)\end{array}$ & $* *$ \\
\hline No alcohol use $(n=237)$ & 22 & 9.3 & 1.00 & $* *$ \\
\hline \multicolumn{5}{|l|}{ Contraception $(n=2442)$} \\
\hline None of nonbarrier $(n=2083)$ & 202 & 9.7 & $\begin{array}{c}0.66 \\
(0.50-0.87)\end{array}$ & $\begin{array}{c}0.71 \\
(0.51-1.00)\end{array}$ \\
\hline Condom $(n=359)$ & 53 & 14.8 & 1.00 & 1.00 \\
\hline
\end{tabular}

$\mathrm{RR}$, relative risk; $\mathrm{OR}$, odds ratio; $\mathrm{Cl}$, confidence interval.

$*_{n}=2484$ unless specific item on obstetric data base left blank.

**Variable excluded from model using multivariate logistic regression with stepwise backward elimination.

cluded tests repeated within two weeks of an initial test in this analysis, tests of cures may have been performed outside this window of time. There was no specific policy in place recommending a test of cure. Therefore, this practice was likely to vary by provider.

Only $87.5 \%$ of our patients had repeat screening during pregnancy, although such screening is the official policy at our institution. There are several possible explanations for this discrepancy. Patients may have delivered prior to the recommended gestational age of repeat testing (34-36 weeks) or may have been noncompliant with clinic visits and may have delivered before returning to the clinic. Finally, individual practitioners may have independently not retested patients whom they considered to be at low risk. There does not seem to be a clinically significant trend among our practitioners to target certain groups for repeat testing.

We found that there exist in our population cer- 
TABLE 2. Risk factors associated with a positive subsequent $C$. trachomatis test during pregnancy after a negative initial test

\begin{tabular}{|c|c|c|c|c|}
\hline Risk factor* & $\begin{array}{c}\text { Positive } \\
\text { test }\end{array}$ & $\begin{array}{l}\text { Percent } \\
\text { positive }\end{array}$ & $\begin{array}{c}\text { RR } \\
(95 \% \mathrm{Cl}) \\
\end{array}$ & $\begin{array}{c}\text { Adjusted OR } \\
(95 \% \mathrm{Cl}) \\
\end{array}$ \\
\hline \multicolumn{5}{|l|}{ Race/ethnicity $(n=1929)$} \\
\hline Black $(n=1397)$ & 100 & 7.2 & $\begin{array}{c}6.61 \\
(2.7 \mid-16.14)\end{array}$ & $\begin{array}{c}7.77 \\
(2.51-24.0)\end{array}$ \\
\hline White $(n=70)$ & 4 & 5.7 & $\begin{array}{c}5.28 \\
(1.45-19.19)\end{array}$ & $\begin{array}{c}8.69 \\
(2.00-37.7)\end{array}$ \\
\hline Other $(n=462)$ & 5 & 1.1 & 1.00 & 1.00 \\
\hline \multicolumn{5}{|l|}{ Age $(n=1929)$} \\
\hline$<25(n=1093)$ & 95 & 8.7 & $\begin{array}{c}5.19 \\
(2.83-9.03)\end{array}$ & $\begin{array}{c}4.12 \\
(2.29-7.42)\end{array}$ \\
\hline$\geq 25(n=836)$ & 14 & 1.7 & 1.00 & 1.00 \\
\hline \multicolumn{5}{|l|}{ Marital status $(n=1929)$} \\
\hline Not currently married $(n=1370)$ & 100 & 7.3 & $\begin{array}{c}4.53 \\
(2.13-8.40)\end{array}$ & $\begin{array}{c}2.08 \\
(0.91-4.72)\end{array}$ \\
\hline Married $(n=559)$ & 9 & 1.6 & 1.00 & 1.00 \\
\hline \multicolumn{5}{|l|}{ Education $(n=1911)$} \\
\hline$<$ High school $(n=519)$ & 41 & 7.9 & $\begin{array}{c}1.62 \\
(1.11-2.35)\end{array}$ & $\begin{array}{c}2.27 \\
(1.47-3.52)\end{array}$ \\
\hline$\geq$ High school $(n=1392)$ & 68 & 4.9 & 1.00 & 1.00 \\
\hline \multicolumn{5}{|l|}{ Gravidity $(n=1929)$} \\
\hline Nulligravid $(n=627)$ & 45 & 7.2 & $\begin{array}{c}1.45 \\
(1.00-2.10)\end{array}$ & $* *$ \\
\hline At least one pregnancy $(n=1302)$ & 64 & 4.9 & 1.00 & $* *$ \\
\hline \multicolumn{5}{|l|}{ History of preterm $(n=1929)$} \\
\hline Prior preterm $(n=192)$ & 8 & 4.2 & $\begin{array}{c}0.72 \\
(0.35-1.45)\end{array}$ & $* *$ \\
\hline No preterm $(n=1737)$ & 101 & 5.8 & 1.00 & $* *$ \\
\hline \multicolumn{5}{|l|}{ History of abortion $(n=1929)$} \\
\hline No prior abortion $(n=|24|)$ & 70 & 5.6 & $\begin{array}{c}1.0 \\
(0.65-1.52)\end{array}$ & $* *$ \\
\hline Prior abortion $(n=688)$ & 39 & 5.7 & 1.00 & $* *$ \\
\hline \multicolumn{5}{|l|}{ Drug use $(n=1929)$} \\
\hline Drug use $(n=71)$ & 3 & 4.2 & $\begin{array}{c}0.74 \\
(0.24-2.28)\end{array}$ & $* *$ \\
\hline No drug use $(n=1858)$ & 106 & 5.7 & 1.00 & $* *$ \\
\hline \multicolumn{5}{|l|}{ Alcohol use $(n=1929)$} \\
\hline Alcohol use $(n=180)$ & 6 & 3.3 & $\begin{array}{c}0.57 \\
(0.25-1.27)\end{array}$ & $* *$ \\
\hline No alcohol use $(n=1749)$ & 103 & 5.9 & 1.00 & $* *$ \\
\hline \multicolumn{5}{|l|}{ Contraception $(n=1897)$} \\
\hline None or nonbarrier $(n=1626)$ & 85 & 5.2 & $\begin{array}{c}0.62 \\
(0.40-0.96)\end{array}$ & ** \\
\hline Condom $(n=271)$ & 23 & 8.5 & 1.00 & ** \\
\hline
\end{tabular}

$\mathrm{RR}$, relative risk; OR, odds ratio; $\mathrm{Cl}$, confidence interval.

$*_{n}=1929$ unless specific item on obstetric data base left blank.

**Variable excluded from model using multivariate logistic regression with stepwise backward elimination.

tain groups that are at high risk for having a positive subsequent $C$. trachomatis test after a negative initial test. This may be secondary to new-onset infection in pregnancy or due to a false-negative initial test, since the sensitivity of the screening tests used is less than $100 \% .{ }^{24}$ Factors that were found to be independently associated with a positive subsequent test after a negative initial test were similar to the risk factors for a positive initial test and include black race or ethnicity, age less than 25 , unmarried status, and less than a high-school education. In our population, we found that white patients were significantly more likely to have a positive repeat test than those designated nonblack and nonwhite (primarily Hispanic), although whites were no more likely to have a positive initial 
test. Although often cited as a risk factor for $C$. trachomatis, ${ }^{3-6}$ a history of sexually transmitted disease prior to pregnancy was unable to be determined from the database.

There were several limitations to this study. The true incidence of $G$. trachomatis infection in our population is unknown because tissue culture for $C$. trachomatis (which was considered the gold standard) was not available at Grady Memorial Hospital. Although having a positive $G$. trachomatis test makes an individual highly likely to have a $C$. trachomatis infection, the positive predictive value of a test will vary among populations. Another limitation to this study is the inability to extrapolate these results to other populations. The demographic and historical risk factors identified in this study may not be valid in a nonindigent population or in women who do not present for prenatal care.

In conclusion, this study suggests that in a highrisk, indigent, obstetric population there exist subgroups of patients who are at increased risk for $C$. trachomatis infection. It is important to identify these patients, because many of the potentially adverse maternal and fetal outcomes associated with C. trachomatis can be prevented by antepartum screening and treatment. ${ }^{23}$ Women in our population who should be retested for $C$. trachomatis in pregnancy include at least those who initially test positive, are less than 25 years old, are black or white, and have less than a high school education. The testing of women without any of the above risk factors should be based on clinical judgment. Further studies are necessary to identify women who do not need to be retested, to determine the optimal frequency and gestational age for testing, to determine the cost and efficacy of repeat screening, and to determine whether repeat screening improves maternal or fetal outcome.

\section{REFERENCES}

1. Centers for Disease Control: 1993 sexually transmitted diseases treatment guidelines. MMWR 42(RR14):1102, 1993.

2. Thompson SE, Washington AE: Epidemiology of sexually transmitted Chlamydia trachomatis infections. Epidemiol Rev 5:96-123, 1983.

3. McGregor JA, French JI: Chlamydia trachomatis infection during pregnancy. Am J Obstet Gynecol 164:1782-1789, 1991.
4. Faro S: Chlamydia trachomatis infection in women. J Reprod Med 30:273-278, 1985.

5. American College of Obstetricians and Gynecologists: Gonorrhea and chlamydial infections. ACOG Technical Bulletin 190: March 1994.

6. Sweet RL, Gibbs RS: Infectious Diseases of the Female Genital Tract. 3rd ed. Baltimore, MD: Williams \& Wilkins, pp 68-71, 1995.

7. Ryan GM, Abdella TN, McNeeley SG, Baselski VS, Drummond DE: Chlamydia trachomatis infection in pregnancy and effect of treatment on outcome. Am J Obstet Gynecol 162:34-39, 1990.

8. Gravett MG, Nelson HP, DeRouen T, Critchlow G, Eschenbach DA, Holmes KK: Independent associations of bacterial vaginosis and Chlamydia trachomatis infection with adverse pregnancy outcome. JAMA 256:18991903, 1986.

9. Cohen I, Veille JC, Calkins BM: Improved pregnancy outcome following successful treatment of chlamydial infection. JAMA 263:3160-3163, 1990.

10. Martin DH, Koutsky L, Eschenbach DA, et al.: Prematurity and perinatal mortality in pregnancies complicated by maternal chlamydial trachomatis infections. JAMA 247:1585-1588, 1982.

11. Martius J, Krohn MA, Hillier SL, Stamm WE, Holmes KK, Eschenbach DA: Relationships of vaginal lactobacillus species, cervical Chlamydia trachomatis, and bacterial vaginosis to preterm birth. Obstet Gynecol 71:8995, 1988.

12. Moller BR, Ahrons S, Laurin J, Mardh P: Pelvic infection after elective abortion associated with Chlamydia trachomatis. Obstet Gynecol 59:210-213, 1982.

13. Giertz G, Kallings I, Nordenvall, Fuchs, T: A prospective study of Chlamydia trachomatis infection following legal abortion. Acta Obstet Gynecol Scand 66:107-109, 1987.

14. Wager GP, Martin DH, Koutsky L, et al.: Puerperal infectious morbidity: Relationship to route of delivery and to antepartum Chlamydia trachomatis infection. Am J Obstet Gynecol 138:1028-1033, 1980.

15. Cytryn A, Sen P, Chung HR, Raina S, Cooper R, Louria DB: Severe pelvic infection from Chlamydia trachomatis after cesarean section. JAMA 247:1732-1734, 1982.

16. Alexander ER, Harrison HR: Role of Chlamydia trachomatis in perinatal infection. Rev Infect Dis 5:713-719, 1983.

17. Schacter J, Grossman M, Sweet RL, Holt J, Jordan C, Bishop E: Prospective study of perinatal transmission of Chlamydia trachomatis. JAMA 255:3374-3377, 1986.

18. Hammerschlag MR, Anderka M, Semine DZ, McComb D, McCormack WM: Prospective study of maternal and infantile infection with Chlamydia trachomatis. Pediatrics 64:142-148, 1979.

19. Schacter J, Holt J, Goodner E, Grossman M, Sweet R, Mills J: Prospective study of chlamydial infection in neonates. Lancet 2:377-380, 1979. 
20. Frommel GT, Rothenberg R, Wang S-P, et al.: Chlamydial infection of mothers and their infants. J Pediatr 95:28-32, 1979.

21. Chandler JW, Alexander ER, Pheiffer TA, Wang S-P, Holmes KK, English M: Ophthalmia neonatorum associated with maternal chlamydial infections. Trans Am Acad Ophthalmol Otolartngol 83:302-308, 1977.

22. Heggie AD, Lumicao CG, Stuart LA, Gyues MT: Chla- mydia trachomatis infection in mothers and infants. A prospective study. Am J Dis Child 135:507-511, 1981.

23. Allaire A, Nathan L, Martens MG: Chlamydia trachomatis: management in pregnancy. Infect Dis Obstet Gynecol 3:82-88, 1995.

24. Centers for Disease Control: Recommendations for the prevention and management of Chlamydia trachomatis infections, 1993. MMWR RR-12:1-39, 1993. 


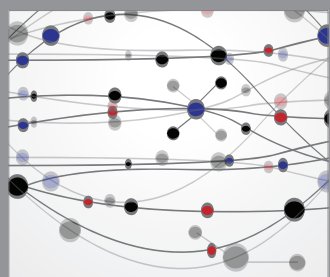

The Scientific World Journal
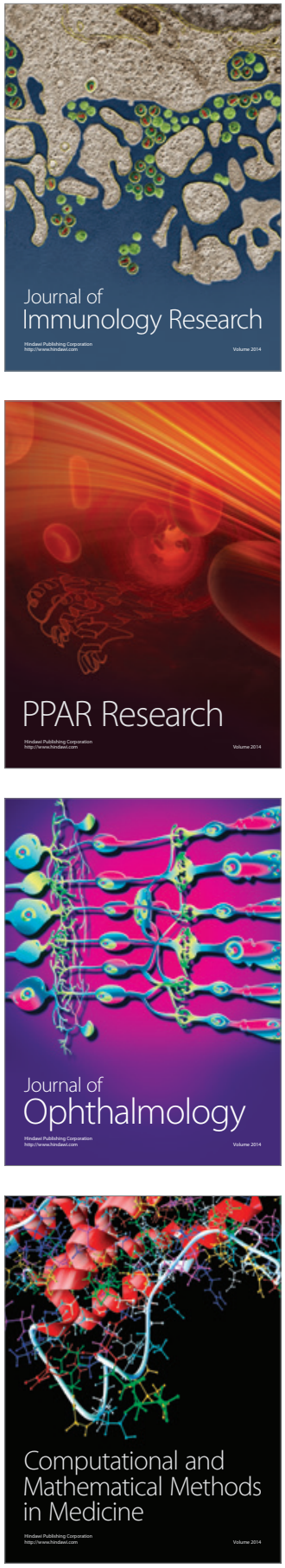

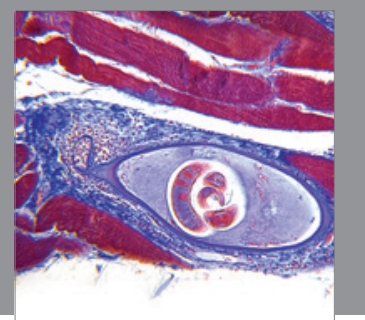

Gastroenterology

Research and Practice
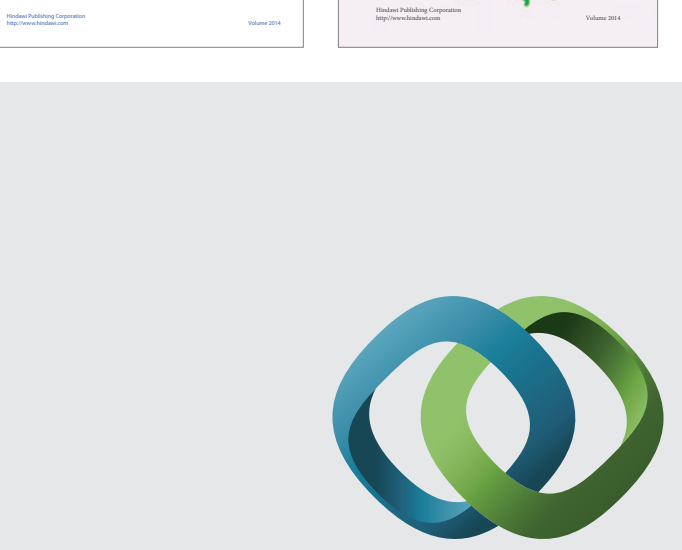

\section{Hindawi}

Submit your manuscripts at

http://www.hindawi.com
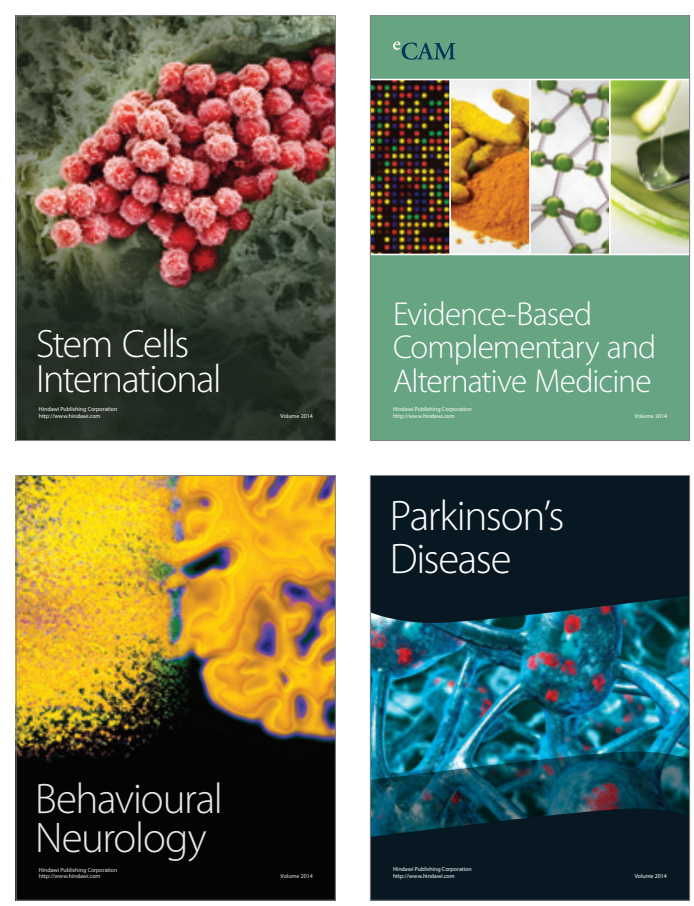

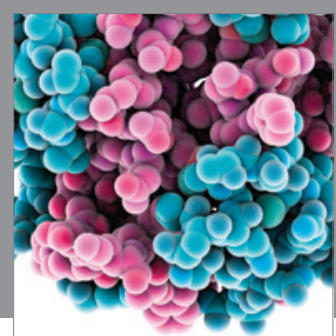

Journal of
Diabetes Research

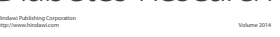

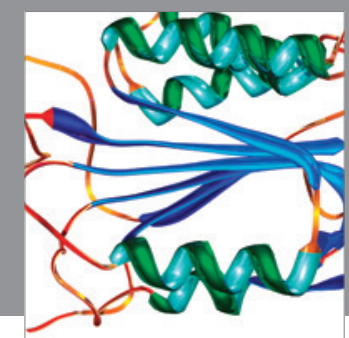

Disease Markers
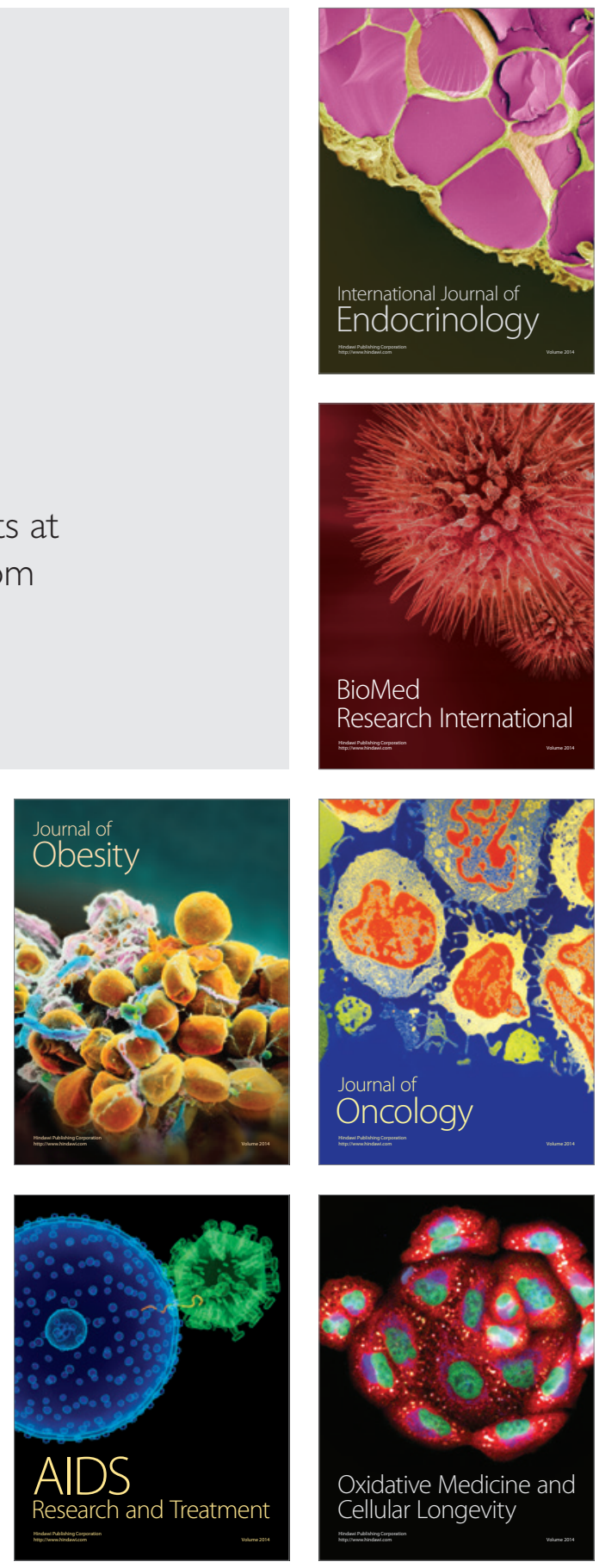